\title{
Convective Heat and Mass Transfer to Fluids from a Rotating Sphere
}

\author{
Abdullah A. Kendoush, PhD \\ Energy Engineering Dept. \\ College of Engineering \\ University of Baghdad \\ Baghdad - Iraq
}

\author{
Yasin K. Salman, PhD \\ Energy Engineering Dept. \\ College of Engineering \\ University of Baghdad \\ Baghdad - Iraq
}

\author{
Farquid Mohammed Al-Janabi \\ Energy Engineering Dept. \\ College of Engineering \\ University of Baghdad \\ Baghdad - Iraq
}

\begin{abstract}
Convective heat and mass transfer from a rotating sphere have been study here. The study cases were divided into the rotating sphere in an axial flow and in still fluid. The heat transfer is a major part in this study because the mass transfer that we got was from analogy. The heat transfer from rotating sphere in an axial flow was solved by taking the advantage of Merk's method, with uniform wall temperature (UWT) and uniform heat flux (UHF) heating conditions, while in still fluid we obtained a new equation for heat transfer for constant wall temperature heating condition. The result was that the heat transfer from the (UHF) case is greater than (UWT) case, while booth cases are increased with the rotation parameter (B) and Prandtl number. Now, for the still fluid case, the heat transfer increases with rotational Reynolds number and with Prandtl number. The mass transfer case had been obtained by the analogy, and because of that we got almost the same equations but with different coefficients and with the same cases that we dealt with heat transfer. A central finite deference method was used to solve fi, gi and $\theta i$ 's parameters for the case of heat and mass transfer from a rotating sphere.
\end{abstract}

\section{Keywords}

Heat Transfer, Mass Transfer, Rotating Sphere in an Axial Flow, Rotating sphere in still Flow.

\section{INTRODUCTION}

The heat transfer from a rotating body (sphere) in flow is important in the problems involving projectile motions, reentry missile behavior, fiber coating applications and rotary machine design. While in the mass transfer from rotating bodies of revolution in a stream has applications in many industrial processes, in chemical or electrochemical engineering, important in determining the transport process between particles and in particle - fluid mixed flow, also in purely hydrodynamic interests. The heat and mass transfer from a rotating sphere in still fluid have the interest in fluid mechanics, metrology, astrophysics and aeronautical engineering. Also it is important in several different applications from combustion of fuel droplets to formulation of hailstones. Siekmann [1] utilized his results in the problem of determining the thermal boundary layer of rotating sphere in an axial stream; by taking the velocity distribution results of Hoskin [2] who investigated the velocity distribution in laminar boundary layer of rotating sphere in an incompressible fluid having uniform flow. Siekmann, in his method expressed the temperature distribution as a power series expansion and presented his results for infinite Reynolds number with Prandtl number (0.7) and (1.0). Chao and Greif [3] have described the heat and mass transfer in laminar forced convection over a rotating body of revolution.
The analysis introduced a unique coordinate transformation, which makes it possible to express the solution of the energy boundary layer equation in terms of universal functions. They had also shown that the same analysis could be used for a rotating body of revolution with and without axial forced flow.

Lee et-al [4] has described a procedure for the calculation of momentum and heat transfer rates through laminar boundary layers over rotating axisymmetric bodies in forced flow. They applied appropriate coordinates transformation and Merk's [5] type of series. The governing momentum equations have been expressed as a set of coupled ordinary differential equations that depends on wedge parameter and rotation parameter. Konno et-al [6] has studied the heat transfer from a rotating sphere in an air flow and in still air. The heat transfer coefficients were varied by changing the dimensionless rotation parameter $(\mathrm{aw} / \mathrm{u})$ value above 3.0. At rotation parameter below 0.7 the influence of rotation was negligible. The influence of the buoyancy forces on a rotating sphere which is situated in an axial flow has been studied by Le Palec and Daguenet [7] by means of Merk's series technique. This method being adapted to pure axial forced convection problems, only small and moderate values of the buoyancy and rotation parameters have been chosen and Prandtl number taken as (1.10) and (100). Their equations were solved for the case of sphere with fourth-order Runge-Kutta method, and the results have shown that the buoyancy effects are adversely by the rotation parameter, which is due to the increasing of centrifugal forces, as the rotation parameter is higher and it became less important as (Pr) increases, this is due to the fact that the thermal boundary layer thickness strongly decreases as $(\mathrm{Pr})$ is higher.

The density difference arising as a result of temperature difference gives rise to buoyancy by Palekar and Rajasekaran [8] who made a theoretical analysis for the flow and heat transfer of a rotating sphere and the effect of the buoyancy force on laminar boundary layer over the rotating sphere in forced flow for two kinds of heating: uniform surface heat flux and uniform wall temperature. Their results were carried out for Prandtl number (0.7), (1.0) and for various values of buoyancy and rotating parameters. It was found that both the friction factor $\left(\mathrm{C}_{\mathrm{f}}\right)$ and the local Nusselt number $(\mathrm{Nu})$ increase with the increasing of the buoyancy force. The local free stream velocity increases with buoyancy, which in turn, affects friction coefficient and Nusselt number. For an equivalent buoyancy effect, heating by uniform surface heat flux yields larger local Nusselt number than heating by uniform wall temperature. The power series of several dimensionless variables are used by Le Palec and Daguenet [9] for the laminar mixed convection about an isothermal 
rotating sphere in a stream in order to study the threedimensional effect of the flow when the angle $\beta$ (the angle between the direction of forced flow and the axis of rotation) is not equal to zero. The mathematical model leads to determination of the local and average heat transfer rates and the components of the local friction factor. Results are first given for gases with Prandtl number of unity. Finally, experimental results which were obtained by electrochemical method were compared with the theoretical ones for a Schmidt number of (2730).

The theoretical analysis of laminar mixed convection around a rotating sphere in a stream was presented by Le Palec [10]. His results showed the effect of the viscous dissipation in the boundary layer. A new correlation for the average Nusselt (Sherwood) number presented for the Prandtl (Schmidt) number ranging from 0.7 to 100 (25 to 2730) and negligible viscous dissipative effects. This correlation is validated with numerical and experimental results. It can be used for the entire mixed convection regime, under buoyancy assisting flow and uniform wall temperature conditions. Nusselt number was presented by Al-Jamal et-al [11] as a function of Reynolds number and Prandtl number for a Laminar flow about a non -rotating sphere. The sphere rotation was expressed in terms of Taylor number (Ta) and Prandtl number $(\mathrm{Pr})$ is ranging between $(0.2)$ to $(0.7)$. The governing equations were solved numerically using finite difference method for constant wall temperature and constant heat flux conditions. Hossain and Takhar [12] were investigated the interaction of the steady mixed convection boundary layer flow past a rotating impermeable body placed in a uniform stream moving opposite to the gravitational force and parallel to the axes of the body of revolution with uniform surface temperature and uniform thermal radiation. Numerical simulations of the boundary layer equations are performed using the local non-similarity method as well as an implicit finite-difference method.

The flow and the convection heat transfer characteristics of sphere spinning about its diameter in still flow (quiescent fluid) are closely related. Stockes [13] gave a quite accurate description of the flow mechanism: "The sphere acts like a centrifugal fan, the motion of a flow outwards the poles, superimposed on a motion of rotation". The problem of the boundary layer on a sphere rotating with uniform angular velocity in an unbounded fluid at rest had been considered theoretically by Howarth [14] who set up the appropriate boundary layer equations and obtained an approximate solution by means of the Karaman momentum integral method, for the case of an incompressible fluid. He was able to deduce that fluid was drawn in towards the sphere along the axis of rotation and moved down over the surface of the sphere towards the equator where the boundary layers originating at opposite poles collided. The angular momentum in steady flow would be continuously transformed from the sphere to infinity via the redial jet. This argument was presented by Nigam [15] who said that the flow must meet at the equator there would be no actual collision because the velocity of flow of the fluid towards the equator would tend to zero as the equator was approached. Kreith et-al[16] investigated experimentally and theoretically the flow engendered by convection heat transfer from a rotating sphere over ranges of Reynolds numbers $\left(\operatorname{Re}_{\mathrm{r}}\right)$ from $(0)$ to $\left(9 \times 10^{5}\right)$, Grashof number $(\mathrm{Gr})$ from $\left(7 \times 10^{4}\right)$ to $\left(3 \times 10^{9}\right)$ and Prandtl numbers $(\operatorname{Pr})$ from $(0.024)$ to $(217)$. For $(\operatorname{Pr})$ between 4 to 214 and $\left(\mathrm{Re}_{\mathrm{r}}\right)$ below $\left(5 \times 10^{4}\right)$ the average Nusselt number $\left(\mathrm{Nu}_{\text {av }}\right)$ for cooling as well as heating was found to be in reasonably good agreement with the results of a theoretical analysis based on a solution of the boundary layer equations in which the boundary layer thickness around the sphere was assumed to be uniform.

Banks [17] has used his earlier result of the laminar velocity distribution in the boundary layer equations for the flow arising from a rotating sphere in a fluid at rest by using these results, the thermal boundary layer characteristics for uniformly heated sphere. Dorfman and Mironova [18] have solved analytically the thermal boundary layer at rotating axisymmetric surface problem by Dorodnisyn's transformation for the case of a compressible gas, the velocity of which is a linear function of temperature. The profile of temperature and components of the velocity vector were presented in a series form expanded over parameters describing the sphere of the meridional surface when their results are integrated over the entire sphere surface.

The problems of heat transfer at high Peclet numbers $(\mathrm{Pe})$ from a sphere freely rotating in a simple shear field was dealt by Acrivos [19] who considered theoretically the case of small shear Reynolds numbers. He showed that there are many respects similar to that of heat transfer past freely rotating cylinder, which was solved by Frankel and Acrivos [20]. An approximate method of solution was developed by taking the advantage of the close analogy between the two cases and gave an asymptotic Nusselt number for Peclet number $\mathrm{Pe} \rightarrow \infty$ is 9 (i.e. 4.5 times its value for pure conduction). Eastop [21] added some experimental result for the case when a sphere rotating in a plane at right angles to the following air. Results were also given for a sphere rotating in stationary air. A series of tests was undertaken for a sphere in still air, for Grashof number of $\left(6.5 \times 10^{5}\right)$ and an infinite Reynolds numbers.

For the heat transfer problem in a linear flow at Reynolds number $\operatorname{Re}<<1$, Poe and Acrivos [22] developed an asymptotic solution to the convection problem for very large Peclet number $(\mathrm{Pe})$, for an infinity large heated cylinder and small heated sphere. In the case of uniform flow, where the streamlines emanate from upstream infinity, the transport of heat takes place, both by conduction and convention. At high Peclet numbers, heat transfer rates from particle to a surrounding fluid depend primarily on the structure of the flow near the heated particle, i.e. they depend on whether the stream lines near the particle are open or closed.

Now, for the mass transfer case, the average and local mass transfer coefficient for a rotating sphere in an axial stream were studied by Furuta et-al[23] and measured by an electrochemical method over a range of rotational Reynolds number $\left(\operatorname{Re}_{\mathrm{r}}\right)$ from $\left(10^{3}\right)$ to $\left(5 \times 10^{4}\right)$ and four kinds of stream Reynolds number $\left(\operatorname{Re}_{\infty}\right)$. Fifteen isolated electrodes were used to obtain the local mass transfer rate. The convective diffusion equation for laminar boundary layer on the sphere was isolated by the light hill transformation on the basis of numerically calculated shear stress distribution by the calculated average Sherwood number $\left(\mathrm{Sh}_{\mathrm{av}}\right)$.

Furuta et-al[24] also calculated the local and average mass transfer coefficient from a rotating sphere and measured electrochemical method when the angle $(\beta)$ between the axis of rotation and the direction of the uniform stream were both $\left(45^{\circ}\right)$ and $\left(90^{\circ}\right)$. For measurements of the local mass transfer rates, circular isolated electrodes of $(2 \mathrm{~mm})$ diameter were used, and the time averaged values and the variations of the local mass transfer rates were obtained by processing the signal from each isolated electrode during some revolutions. Moreover, on the basis of measurements of average mass 
transfer coefficients, new empirical equations were obtained with which they have been correlated well for $\beta=0^{\circ}, 45^{\circ}$ and $90^{\circ}$.

\section{ANALYSIS OF HEAT TRANSFER FROM A ROTATING SPHERE IN AN AXIAL FLOW}

Consider steady, laminar, non-dissipative, constant property and incompressible boundary layer flow around a rotating sphere place in a uniform axial stream with its axis of rotation parallel to the free stream velocity. The rotating sphere has two heating cases, either a uniform wall temperature, or a uniform surface heat flux.

Let $\mathrm{x}, \mathrm{y}$ and $\mathrm{z}$ be a non-rotating orthogonal curvilinear coordinate system with corresponding velocity components $\mathrm{u}$, $\mathrm{v}$ and $\mathrm{w}$. If $(\mathrm{r})$ is the radial distance from a surface element to the axis of symmetry, as shown in Fig. (1), the governing boundary layer equations are given by:

The continuity equation is

$\frac{\partial}{\partial \mathrm{x}}(\mathrm{ru})+\frac{\partial}{\partial \mathrm{y}}(\mathrm{rv})=0$

The $\mathrm{x}$, $\mathrm{y}$ momentum equations are:

$u \frac{\partial u}{\partial x}+v \frac{\partial u}{\partial y}-\frac{w^{2}}{r} \frac{d r}{d x}=U_{e} \frac{d U_{e}}{d x}+v \frac{\partial^{2} u}{\partial y^{2}}$

$\mathrm{u} \frac{\partial \mathrm{w}}{\partial \mathrm{x}}+\mathrm{v} \frac{\partial \mathrm{w}}{\partial \mathrm{y}}+\frac{\mathrm{uw}}{\mathrm{r}} \frac{\mathrm{dr}}{\mathrm{dx}}=v \frac{\partial^{2} \mathrm{w}}{\partial \mathrm{y}^{2}}$

And the energy equation is:

$\mathrm{u} \frac{\partial \mathrm{T}}{\partial \mathrm{x}}+\mathrm{v} \frac{\partial \mathrm{T}}{\partial \mathrm{y}}=\alpha \frac{\partial^{2} \mathrm{~T}}{\partial \mathrm{y}^{2}}$

For the $\mathrm{x}, \mathrm{y}$ momentum equations, the effect of the viscose dissipation is neglected, to the two terms refers to there are omitted. Now, the solution of heat transfer coefficient for the above equations will be discussed according to the sphere heating conditions

\subsection{Uniform Wall Temperature (UWT)}

This is the case of a rotating sphere in an axial flow with temperature heating condition. Here the boundary conditions are:

$u=v=0, w=\Omega r, T=T_{w}$ for $y=0$

$u=U_{e}, v=w=0, T=T_{\infty}$ for $y \rightarrow \infty$

Where:

$\mathrm{U}_{\mathrm{e}(\mathrm{x})}$ : Is the velocity of mainstream at the edge of the boundary layer.

$\Omega$ : The angular velocity of the rotating sphere, which is assumed to be constant

$\mathrm{T}_{\mathrm{w}}$ and $\mathrm{T}_{\mathrm{a}}$ : The wall and ambient temperatures respectively and are constant.

To solve the set of partial differential equations (1), (2), (3) and (4), we introduce a stream function $\psi(\mathrm{x}, \mathrm{y})$ defined by

$$
\mathrm{u}=\frac{\mathrm{a}}{\mathrm{r}} \frac{\partial \psi}{\partial \mathrm{y}} \quad ; \quad v=\frac{-\mathrm{a}}{\mathrm{r}} \frac{\partial \psi}{\partial \mathrm{x}}
$$

Such that, the continuity equation (Eq.(1)) is identically satisfied. The $(\mathrm{x}, \mathrm{y})$ coordinate system is transformed into the dimensionless $(\xi, \eta)$ system, using the advantage of Lee et-al [4], will be:

$\mathrm{x}=\Longrightarrow \xi=\int_{0}^{\mathrm{x}} \frac{\mathrm{U}_{\mathrm{e}}}{\mathrm{U}_{\infty}}\left(\frac{\mathrm{r}}{\mathrm{a}}\right)^{2} \frac{\mathrm{dx}}{\mathrm{a}}$

$\mathrm{y}=\Longrightarrow \eta=\left(\frac{\mathrm{Re}_{\infty}}{2 \xi}\right)^{1 / 2} \frac{\mathrm{U}_{\mathrm{e}}}{\mathrm{U}_{\infty}}\left(\frac{\mathrm{r}}{\mathrm{a}}\right) \frac{\mathrm{y}}{\mathrm{a}}$ $\psi(\mathrm{x}, \mathrm{y})=\mathrm{U}_{\infty} \mathrm{a}\left(\frac{2 \xi}{\mathrm{Re}_{\infty}}\right)^{1 / 2} \mathrm{f}(\xi, \eta)$

Using equations (7), (8) and (9), equation (6) becomes $\mathrm{u}=\mathrm{U}_{\mathrm{e}} \frac{\partial \mathrm{f}}{\partial \eta}$

$\mathrm{v}=\frac{-\mathrm{r}}{\mathrm{a}} \frac{\mathrm{U}_{\mathrm{e}}}{\left(2 \xi \mathrm{Re}_{\infty}\right)^{1 / 2}}\left[\mathrm{f}+2 \xi \frac{\partial \mathrm{f}}{\partial \xi}+\left(\Lambda+\frac{2 \xi}{\mathrm{r}} \frac{\mathrm{dr}}{\mathrm{d} \xi}-1\right) \eta \frac{\mathrm{df}}{\mathrm{d} \eta}\right]$

$\mathrm{u}(\mathrm{x}, \mathrm{y}), \mathrm{v}(\mathrm{x}, \mathrm{y}), \mathrm{w}(\mathrm{x}, \mathrm{y})$ and $\mathrm{T}(\mathrm{x}, \mathrm{y})$ are transformed into dimensionless functions $\mathrm{f}, \mathrm{g}$ and $\theta$ as follows:

And

$\mathrm{w}(\mathrm{x}, \mathrm{y})=\mathrm{r}(\mathrm{x}) \Omega g(\xi, \eta)$

Now, the wedge parameter $(\Lambda)$ is defined by:

$\Lambda=\frac{2 \xi}{U_{e}} \frac{d U_{e}}{d \xi}$

The temperature distribution for this case is:

$\theta(\xi, \eta) \eta=\frac{T-T_{\infty}}{T_{w}-T_{\infty}}$

Using the above transformations, the momentum and energy equations (2), (3) and (4) with the boundary conditions Eq. (5) may be written as:

$$
\begin{array}{ll}
f^{\prime \prime \prime}+f f^{\prime \prime}+\Lambda\left(1-f^{\prime 2}\right)+\frac{2 \xi}{r} \frac{d r}{d \xi}\left[\frac{r^{2} \Omega^{2}}{U_{e}^{2}}\right] g^{2}=2 \xi \frac{\partial\left(f^{\prime}, f\right)}{\partial(\xi, \eta)} \\
g^{\prime \prime}+f g^{\prime}-\frac{4 \xi}{r} \frac{d r}{d \xi} g f^{\prime}=2 \xi \frac{\partial(g, f)}{\partial(\xi, \eta)} & --(15) \\
P r^{-1} \theta^{\prime \prime}+f \theta^{\prime}=2 \xi \frac{\partial(\theta, f)}{\partial(\xi, \eta)} & --(16)
\end{array}
$$

With the boundary conditions:

$$
\begin{aligned}
& f=f^{\prime}=\theta=0: \quad g=1 \text { for } \eta=0 \\
& f^{\prime}=\theta=1 \quad: \quad g=0 \text { for } \eta \rightarrow \infty
\end{aligned}
$$

Noting that the primes denote differentiation with respect to $(\eta)$ and

$\frac{\partial\left(f^{\prime}, f\right)}{\partial(\xi, \eta)}=\left\lfloor f^{\prime} \frac{\partial}{\partial} \frac{f^{\prime}}{\xi}-f^{\prime \prime} \frac{\partial f}{\partial \xi}\right\rfloor$

Is called the Jacobian. For the sphere, these are some parameters we may need:

$$
\frac{\mathrm{r}}{\mathrm{a}}=\sin \emptyset \quad, \quad \frac{\mathrm{U}_{\mathrm{e}}}{\mathrm{U}_{\infty}}=\frac{3}{2} \sin \emptyset
$$

$$
\frac{4 \xi}{\mathrm{r}} \frac{\mathrm{dr}}{\mathrm{d} \xi}=2 \Lambda \quad, \quad \frac{4 \xi}{\mathrm{r}} \frac{\mathrm{dr}}{\mathrm{d} \xi} \frac{\mathrm{r}^{2} \Omega^{2}}{\mathrm{U}_{\mathrm{e}}^{2}}=\mathrm{B} \Lambda
$$

The rotation parameter $\beta=\frac{4}{9}\left(\frac{\alpha \Omega}{\mathrm{U}_{\mathrm{e}}}\right)^{2}$

Following Chao and Fagbenle [25], we write expressions for $\mathrm{f}, \mathrm{g}$ and $\theta$ in the form of Merk's series as:

$$
\begin{aligned}
& f(\xi, \eta)=f_{0}(\Lambda, \eta)+2 \xi \frac{d \Lambda}{d \xi} f_{1}(\Lambda, \eta)+4 \xi^{2} \frac{d^{2} \Lambda}{d \xi^{2}} f_{2}(\Lambda, \eta)+ \\
& \left\lfloor 2 \xi \frac{d \Lambda}{d \xi}\right\rfloor^{2} f_{3}(\Lambda, \eta)+\cdots . .
\end{aligned}
$$

$g(\xi, \eta)=g_{0}(\Lambda, \eta)+2 \xi \frac{d \Lambda}{d \xi} g_{1}(\Lambda, \eta)+4 \xi^{2} \frac{d^{2} \Lambda}{d \xi^{2}} g_{2}(\Lambda, \eta)+$

$\left\lfloor 2 \xi \frac{\mathrm{d} \Lambda}{\mathrm{d} \xi}\right\rfloor^{2} g_{3}(\Lambda, \eta)+\cdots \ldots$

$$
\begin{aligned}
& \theta(\xi, \eta)=\theta_{0}(\Lambda, \eta)+2 \xi \frac{d \Lambda}{d \xi} \theta_{1}(\Lambda, \eta)+4 \xi^{2} \frac{d^{2} \Lambda}{d \xi^{2}} \theta_{2}(\Lambda, \eta)+ \\
& \left\lfloor 2 \xi \frac{d \Lambda}{d \xi}\right\rfloor^{2} \theta_{3}(\Lambda, \eta)
\end{aligned}
$$


Substituting equations (20) - (22) into equations (15) - (17) and collection terms free of $(\mathrm{d} \Lambda / \mathrm{d} \xi)$ and then terms common to $(2 \xi(\mathrm{d} \Lambda / \mathrm{d} \xi)),\left(4 \xi^{2}\left(\mathrm{~d}^{2} \Lambda / \mathrm{d} \xi^{2}\right)\right)$ etc., one obtains a sequence of coupled ordinary differential equations. For the zero order term:

$$
\begin{aligned}
& \mathrm{f}_{0}^{\prime \prime \prime}+\mathrm{f}_{0} \mathrm{f}_{0}^{\prime \prime}+\Lambda\left\lfloor 1-\left(\mathrm{f}_{0}\right)^{2}+\mathrm{B} g_{0}^{2}\right\rfloor=0 \\
& g_{0}^{\prime \prime}+\mathrm{f}_{0} g_{0}^{\prime}-2 \Lambda \mathrm{f}^{\prime} g_{0}=0 \\
& \operatorname{Pr}^{-1} \theta_{0}^{\prime \prime}+\operatorname{Pr} \mathrm{f}_{0} \theta_{0}^{\prime}=0 \\
& \text { With } \\
& \mathrm{f}_{0}(\Lambda, 0)=\mathrm{f}_{0}^{\prime}(\Lambda, 0)=\theta_{0}(\Lambda, 0), \mathrm{g}_{0}(\Lambda, 0)=1 \\
& \mathrm{f}_{0}^{\prime}(\Lambda, \infty)=\theta_{0}(\Lambda, \infty), \quad \mathrm{g}_{0}(\Lambda, \infty)=0
\end{aligned}
$$

For the first and higher order terms:

$$
\begin{array}{r}
\mathrm{f}_{1}^{\prime \prime}+\mathrm{f}_{0} \mathrm{f}_{1}^{\prime \prime}-2(1-\Lambda) f_{0}^{\prime} f_{1}^{\prime}+3 \mathrm{f}_{0}^{\prime \prime} \mathrm{f}_{1}+2 \mathrm{~B} \Lambda g_{0} g_{1}=\frac{\partial\left(f_{0}^{\prime}, \mathrm{f}_{0}\right)}{\partial(\Lambda, \eta)} \\
g_{1}^{\prime \prime}+\mathrm{f}_{0} g_{1}^{\prime}-2 f_{0}^{\prime} g_{1}-2 \Lambda\left(f_{0}^{\prime} g_{0}+g_{1} f_{0}^{\prime}\right)+3 \mathrm{f}_{1} g_{0}^{\prime}=\frac{\partial\left(g_{0}, \mathrm{f}_{0}\right)}{\partial(\Lambda, \eta)}
\end{array}
$$

$\operatorname{Pr}^{-1} \theta_{1}^{\prime \prime}+\mathrm{f}_{0} \theta_{1}^{\prime}-2 f_{0}^{\prime} \theta_{1}+3 \mathrm{f}_{1} \theta_{0}^{\prime}=\frac{\partial\left(\theta_{0}, \mathrm{f}_{0}\right)}{\partial(\Lambda, \eta)}$

With

$$
\mathrm{f}_{1}(\Lambda, 0)=\mathrm{f}_{1}^{\prime}(\Lambda, 0)=\theta_{1}(\Lambda, 0), \mathrm{g}_{1}(\Lambda, 0)=0
$$$$
\mathrm{f}_{1}^{\prime}(\Lambda, \infty)=\theta_{1}(\Lambda, \infty)=\mathrm{g}_{1}(\Lambda, \infty)=0
$$

And

$\mathrm{f}_{2}^{\prime \prime \prime}+\mathrm{f}_{0} \mathrm{f}_{2}^{\prime \prime}-2(2+\Lambda) \mathrm{f}_{0}^{\prime} \mathrm{f}_{2}^{\prime}+5 \mathrm{f}_{0}^{\prime \prime} \mathrm{f}_{2}+2 \mathrm{~B} \Lambda \mathrm{g}_{0} g_{2}=\mathrm{f}_{0}^{\prime} \mathrm{f}_{1}^{\prime}-$

$\mathrm{f}_{0}^{\prime \prime} \mathrm{f}_{1}$

$g_{2}^{\prime \prime}+\mathrm{f}_{0} g_{2}^{\prime}-4 \mathrm{f}_{0}^{\prime} g_{2}-2 \Lambda\left(g_{0} \mathrm{f}_{2}^{\prime}+g_{2} \mathrm{f}_{0}^{\prime}\right)+5 \mathrm{f}_{2} g_{0}^{\prime}=\mathrm{f}_{0}^{\prime} g_{1}-$

$\mathrm{f}_{1} g_{0}^{\prime}$

$\operatorname{Pr}^{-1} \theta_{2}^{\prime \prime}+\mathrm{f}_{0} \theta_{2}^{\prime}-4 \mathrm{f}_{0}^{\prime} \theta_{2}+5 \mathrm{f}_{2} \theta_{1}=\mathrm{f}_{0}^{\prime} \theta_{1}-\mathrm{f}_{1} \theta_{0}$

With

$\mathrm{f}_{2}(\Lambda, 0)=\mathrm{f}_{2}^{\prime}(\Lambda, 0)=g_{2}(\Lambda, 0)=\theta_{2}(\Lambda, 0)=0$

$\mathrm{f}_{2}^{\prime}(\Lambda, \infty)=g_{2}(\Lambda, \infty)=\theta_{2}(\Lambda, \infty)=0$

Defining the local frictional coefficient in the stream wise direction by:

$C_{f}=\frac{\mu\left(\frac{\partial u}{\partial y}\right)_{y=0}}{\frac{1}{2} \rho U_{\infty}^{2}}$

After transformation, we get:

$$
\begin{aligned}
& \frac{1}{2} \mathrm{C}_{\mathrm{f}} \operatorname{Re}_{\infty}{ }^{1 / 2}=\frac{\mathrm{r}}{\mathrm{a}}\left(\frac{\mathrm{U}_{\mathrm{e}}}{\mathrm{U}_{\infty}}\right)^{2}(2 \xi)^{1 / 2}\left(\mathrm{f}_{0}^{\prime \prime}(\Lambda, 0)+2 \xi \frac{\mathrm{d} \Lambda}{\mathrm{d} \xi} \mathrm{f}_{1}^{\prime \prime}(\Lambda, 0)+\right. \\
& \left.2 \xi^{2} \frac{\mathrm{d}^{2} \Lambda}{\mathrm{d} \xi^{2}} \mathrm{f}_{2}^{\prime \prime}(\Lambda, 0)+\cdots\right)
\end{aligned}
$$

Now, the local Nusselt number for (UWT) case after transformation is:

$$
\begin{aligned}
& \frac{N_{\mathrm{x}}}{\operatorname{Re}_{\infty}^{1 / 2}}=\frac{-\mathrm{r}}{\mathrm{a}}\left(\frac{\mathrm{U}_{\mathrm{e}}}{\mathrm{U}_{\infty}}\right)(2 \xi)^{-1 / 2}\left(\theta_{0}^{\prime}(\Lambda, 0)+2 \xi \frac{\mathrm{d} \Lambda}{\mathrm{d} \xi} \theta_{1}^{\prime}(\Lambda, 0)+\right. \\
& \left.4 \xi^{2} \frac{\mathrm{d}^{2} \Lambda}{\mathrm{d} \xi^{2}} \theta_{2}^{\prime}(\Lambda, \eta)+\cdots\right)
\end{aligned}
$$

\subsection{Uniform surface heat flux (UHF)}

This is the case of a rotating sphere with a uniform surface heat flux heating condition. In this case, the boundary conditions are:

$\mathrm{u}=\mathrm{v}=0, \mathrm{w}=\mathrm{r} \Omega, \mathrm{q}_{\mathrm{w}}=-\mathrm{K}\left(\frac{\partial \mathrm{T}}{\partial \mathrm{y}}\right)_{\mathrm{y}=0}$ for $\mathrm{y}=0$

$\mathrm{u}=\mathrm{U}_{\mathrm{e}}, \mathrm{v}=\mathrm{w}=0, T=\mathrm{T}_{\infty}$ for $\mathrm{y} \rightarrow \infty$

The transformations are the same as in section (2.1) (i.e UWT case) except in equation (14) which will be now replaced by: $\theta(\xi, \eta)=\left\lfloor T(x, y)-T_{\infty}\right\rfloor \operatorname{Re}_{\infty}^{1 / 2} /\left(q_{w} a / K\right)$

Now, the local Nusselt number for (UHF) case after transformations:

$$
\begin{aligned}
& \mathrm{Nu}_{\mathrm{x}} / \operatorname{Re}^{1 / 2}=\mid \theta_{0}(\Lambda, 0)+2 \xi \frac{\mathrm{d} \Lambda}{\mathrm{d} \xi} \theta_{1}(\Lambda, 0)+ \\
& 4 \xi^{2} \frac{\mathrm{d}^{2} \Lambda}{\mathrm{d} \xi^{2}} \theta_{2}(\Lambda, \eta)+\left.\cdots\right|^{-1}
\end{aligned}
$$

The calculation of the surface characteristics begins with an evaluation of the stream wise coordinate $(\xi)$ and the wedge parameter $(\Lambda)$ and its derivatives, their values are:

$\xi=1-1.5 \cos \phi+0.5 \cos ^{2} \phi$

$\Lambda=\frac{\left(4 \cos \phi-6 \cos ^{2} \phi+2 \cos ^{4} \phi\right)}{3 \sin ^{4} \phi}$

$\frac{d \Lambda}{d \xi}=\frac{8(1-\cos \phi)^{3}}{9 \sin ^{8} \phi}$

$\frac{\partial^{2} \Lambda}{\partial \xi^{2}}=\frac{-16}{27 \sin ^{12} \phi}(1-\cos \phi)^{3}(3-5 \cos \phi)$

\section{NUMERICAL ANALYSIS}

The differential equation for $\mathrm{f}_{\mathrm{i}}, \mathrm{g}_{\mathrm{i}}$ and $\theta_{\mathrm{i}}{ }^{\prime} \mathrm{s}(\mathrm{i}=0,1$ and 2$)$ were solved using central finite difference method. Data for nine values of $(\Lambda)$ ranging from $(0.5)$ to $(0.1)$, and three values of $\operatorname{Pr}(0.7,1.0$ and 10$)$ were considered. High accuracy is required of the basic function $\mathrm{f}_{0}$ since the higher order functions in the series are sensitive to its variation. The selection of the integration step size depends on the precision of the numerical results desired, the number of terms used, and the computational time allowed. After several trials, we found that the integration step size is: $\mathrm{h}=\Delta \eta=0.01$. The iteration was to continue until the following conditions are met:

$\left|1-f_{0}^{\prime}\left(\Lambda, \eta_{\infty}\right)\right|<10^{-5}$

And

$g_{0}\left(\Lambda, \eta_{\infty}\right)<10^{-5}$

Where $\left(\eta_{\square}\right)$ denotes the largest value of $(\eta)$. The largest value of $(\eta)$ was taken as $(8)$, because the computed second wall derivative $f_{0} ",(\Lambda, 0)$ exhibited no changes up to the fifth significant digits when the computation was repeated with $\eta$ $>8$.

\section{ANALYSIS AND SOLUTION OF HEAT TRANSFER FROM A ROTATING SPHERE IN STILL FLUID}

An analytical solution for this case is derived by taking an advantage from the work of Zaturska and Banks [26], who gave the following velocity profile for the rotating sphere in a fluid at rest, or quiescent flow

$V_{r}=V_{\theta}=0$

$\mathrm{V}_{\phi}=\Omega \frac{\mathrm{a}^{3}}{\mathrm{r}^{2}} \sin \phi$

And

$\left[\mathrm{V}_{\phi}\right]_{\mathrm{r}=\mathrm{a}}=\Omega \mathrm{a} \sin \phi$

Where: a: Radius of the sphere.

$\Omega$ : The angular velocity of the sphere.

The above velocity field is valid for $\operatorname{Re}_{\infty}<10$

The energy equation in spherical coordinates is:

$\mathrm{Vr} \frac{\partial \mathrm{T}}{\partial \mathrm{r}}+\frac{\mathrm{V} \theta}{\mathrm{r}} \frac{\partial \mathrm{T}}{\partial \theta}+\frac{\mathrm{V} \phi}{\mathrm{r} \sin \theta} \frac{\partial \mathrm{T}}{\partial \phi}=\alpha \frac{\partial^{2} \mathrm{~T}}{\partial \mathrm{r}^{2}}$

Due to the above conditions, the first two terms vanishes, then assuming that: $r \approx a$, then

$\frac{\mathrm{V}_{\phi}}{\mathrm{r} \sin \theta} \frac{\partial \mathrm{T}}{\partial \phi} \approx \frac{\mathrm{V}_{\phi}}{\mathrm{a} \sin \theta} \frac{\partial \mathrm{T}}{\partial \phi}$ 
$\therefore \frac{\mathrm{V}_{\phi}}{\mathrm{a} \sin \theta} \frac{\partial \mathrm{T}}{\partial \phi}=\mathrm{a} \frac{\partial^{2} \mathrm{~T}}{\partial \mathrm{r}^{2}}$

Substitution of Eq.(45) into Eq. (47) gives:

$\frac{\partial \mathrm{T}}{\partial \phi}=\frac{\mathrm{a}}{\Omega} \frac{\partial^{2} \mathrm{~T}}{\partial \mathrm{r}^{2}}$

The solution of the above equation for the constant wall temperature and a non-zero initial temperature is shown by Carslaw and Jeager [27]

$\mathrm{T}=\mathrm{C} \cdot \operatorname{erfc}\left[\frac{\mathrm{r}}{2\left(\frac{\mathrm{a} \phi}{\Omega}\right)^{1 / 2}}\right]$

Where:

C: Constant to be determined

The boundary conditions for this case are:

$\mathrm{T}=0$ at $\mathrm{r} \rightarrow \infty$ and $\mathrm{T}=\mathrm{T}_{0} \quad$ at $\mathrm{r}=0$

$\mathrm{T}=\mathrm{T}_{\mathrm{a}} \cdot \operatorname{erfc}\left[\frac{\mathrm{r}}{2\left(\frac{\mathrm{a} \phi}{\Omega}\right)^{1 / 2}}\right]$

This equation indicates the temperature profile for the case of the rotating sphere in a fluid at rest, and to get the Nusselt number we have to transform the temperature profile to Nusselt number.

$\frac{\partial \mathrm{T}}{\partial \mathrm{r}}=\frac{-2 \mathrm{~T}_{\mathrm{a}}}{\sqrt{\pi}}\left[\frac{1}{2(\mathrm{a} \phi \Omega)^{1 / 2}} \mathrm{e}^{\frac{-\mathrm{r}^{2} \Omega}{4 \mathrm{a} \phi}}\right]$

This equation was taken from Meyers [28], without any other details. To see details one can see the reference.

And

$\left(\frac{\partial T}{\partial r}\right)_{r=0}=-\left(\frac{\Omega}{\pi a \phi}\right)^{1 / 2} \cdot T_{a}$

Now, equation (53) will be presented in $\mathrm{Nu}, \mathrm{Re}_{\mathrm{r}}$ and $\mathrm{Pr}$ :

$\mathrm{Nu}=\frac{1}{\sqrt{2 \pi}}\left(\frac{\mathrm{Re}_{\mathrm{r}} \cdot \mathrm{Pr}}{\phi}\right)^{1 / 2}$

The above equation indicated the local Nusselt number (i.e. $\mathrm{Nu}(\varphi))$. Now, to find the average Nusselt number $\left(\mathrm{Nu}_{\mathrm{av}}\right)$

$\mathrm{Nu}_{\mathrm{av}}=\frac{1}{4 \pi \mathrm{a}^{2}} \int_{0}^{\pi} \mathrm{Nu}(\phi) \cdot 2 \pi \mathrm{a}^{2} \cdot \sin \phi \cdot \mathrm{d} \phi$

(55)

The above equation is the average Nusselt number for the rotating sphere in a fluid at rest.

$$
\therefore \mathrm{Nu}_{\mathrm{av}}=0.3574\left(\operatorname{Re}_{\mathrm{r} .} . \mathrm{Pr}\right)^{1 / 2}
$$

\section{ANALYSIS of MASS TRANSFER}

The corresponding problem in mass transfer can be stated in an analogous method to the previously discussed heat transfer from a rotating sphere for the two cases, in an axial flow and in still flow, particularly when viscous heating is ignored in the latter. We need only to replace temperature by concentration, the thermal boundary layer by concentration boundary layer, the Nusselt number by Sherwood number and the Prandtl number by Schmidt number

\subsection{Rotating sphere in an axial flow}

The mass transfer rate from a rotating sphere in an axial flow can be gained by the analogous method which led to the same of heat transfer result, then the local mass transfer for Eq. (37) is:

$$
\begin{aligned}
& \frac{\mathrm{Sh}_{\mathrm{x}}}{\operatorname{Re}_{\infty}^{1 / 2}}=\frac{-\mathrm{r}}{\mathrm{a}}\left(\frac{\mathrm{U}_{\mathrm{e}}}{\mathrm{U}_{\infty}}\right)(2 \xi)^{-1 / 2}\left(\theta_{0}^{\prime}(\Lambda, 0)+2 \xi \frac{\mathrm{d} \Lambda}{\mathrm{d} \xi} \theta_{1}^{\prime}(\Lambda, 0)+\right. \\
& \left.4 \xi^{2} \frac{\mathrm{d}^{2} \Lambda}{\mathrm{d} \xi^{2}} \theta_{2}^{\prime}(\Lambda, 0)+\cdots\right)
\end{aligned}
$$

And Eq. (39) will be:

$$
\begin{aligned}
& \mathrm{Sh}_{\mathrm{x}} \operatorname{Re}_{\infty}^{1 / 2}=\frac{-\mathrm{r}}{\mathrm{a}}\left(\frac{\mathrm{U}_{\mathrm{e}}}{\mathrm{U}_{\infty}}\right)(2 \xi)^{-1 / 2}\left(\theta_{0}(\Lambda .0)+2 \xi \frac{\mathrm{d} \Lambda}{\mathrm{d} \xi} \theta_{1}(\Lambda .0)+\right. \\
& \left.4 \xi^{2} \frac{\mathrm{d}^{2} \Lambda}{\mathrm{d} \xi^{2}} \theta_{2}(\Lambda .0)+\cdots . .\right)^{-1}
\end{aligned}
$$

\subsection{Rotating sphere in a still fluid}

The mass transfer rate can be given by taking the analogy between heat and mass transfer, and the expression will become the following:

$\mathrm{Sh}_{\mathrm{av}}=0.3574 \mathrm{Re}_{\mathrm{r}}^{1 / 2} \mathrm{Sc}^{1 / 2}$

\section{RESULTS AND DISCUSSIONS \\ 6.1 Introduction}

For the Rotating sphere in an axial flow results, Lee et-al [4] and Palekar [8] works have approximately the same equations obtained in the present work, Eq. (37)

for the (UWT) case, Eq.(40) for the (UHF) case and the present work friction factor $\left(\mathrm{C}_{\mathrm{f}}\right)$ Eq.(36), but they have got different results for the $f, g$ and $\theta$ 's values. While for the Rotating sphere in still fluid situation the results of Kreith etal [16] work, Banks [17] work, Dorfman and Mironova [18] work and Eastop [21] work were used as a previous work to compare with. .Each one of these equations was compared with the present work in Eq. (46), according to present work conditions.

For the mass transfer case, a very limited work was found dealing with mass transfer from a rotating sphere. Therefore our comparison in the present investigation will be with the experimental and analytical investigations carried out by Furuta et-al [23]. Furuta et-al [23] presents experimental and analytical results for a rotating sphere in an axial fluid flow while present an analytical result for the case of a rotating sphere in a sill fluid. The comparison with Furuta et-al [24] was for the uniform wall temperature rotating sphere heating condition only.

\subsection{Heat transfer for a rotating sphere}

\subsection{1 in an axial flow}

Equations were derived to present the predicated heat transfer coefficient and the predicted friction factor for two cases of heating conditions: uniform wall temperature (UWT) and uniform heat flux (UHF). Expressions were obtained using Merk's numerical method and these expressions give Nusselt number in terms of Reynolds number, as in Eq. (37) for UWT heating condition and in Eq.(40) for UHF heating condition while local friction coefficient expression in term of Reynolds number for the average Nusselt number, presented in Eq.(36) for the both heating cases.

The variation of the $\left(\mathrm{Nu}_{\mathrm{x}} / \mathrm{Re}_{\infty}{ }^{1 / 2}\right)$ with the wedge parameter $(\Lambda)$, for different $(\operatorname{Pr})$ number and for $B$ parameter equal to 1 is depicted in Fig. (2) to Fig.(4). Fig. (2) presents the variation for UWT heating condition and it depicted an improvement in local heat coefficients as the $\left(\mathrm{Nu}_{\mathrm{x}} / \mathrm{Re}_{\infty}{ }^{1 / 2}\right)$ value increases with the increasing of $(\Lambda)$, and Pr. The local heat transfer coefficient suffers a slight reduction for the UHF heating condition as that shown in Fig. (3) as it depicts the variation of $\left(\mathrm{Nu}_{x} / \mathrm{Re}_{\infty}{ }^{1 / 2}\right)$ value with same range of wedge $(\Lambda)$ and same range of $\operatorname{Pr}$ number used in Fig.(2). The comparison between two different heating conditions on the local heat transfer process is shown in Fig. (4) as it presents the variation of $\left(\mathrm{Nu}_{\mathrm{x}} / \mathrm{Re}_{\infty}{ }^{1 / 2}\right)$ values, obtained by dividing the results of UWT heating condition to the results of (UHF) heating condition, with the wedge parameter $(\Lambda)$. The figure exhibits a trend similar to that obtained in Fig. (2). The B 
parameter shows a very insignificant effect on the heat transfer results as its values changed from 1 to 10 .

Fig.(5) shows the variation of the friction coefficient $\left(\mathrm{C}_{\mathrm{f}}\right)$ values with the wedge parameter $(\Lambda)$, for different $\beta$ parameter ( $\beta=1,4$ and 10$)$, obtained from Eq. (36). $C_{\mathrm{f}}$ results exhibit independency on Pr number and the results reveal a clear escalation in $C_{f}$ value with $B$ parameter and the variation almost has a Maxwell distribution with $(\Lambda)$ parameter.

The comparison of present work with the previous work, presented as the variation of $\left(\mathrm{Nu}_{\mathrm{x}} / \mathrm{Re}_{\infty}{ }^{1 / 2}\right)$ with wedge parameter for same Pr number and $\beta$ parameter, is plotted in the Fig.(6) and Fig.(7). The comparison for the UWT heating situation with Lee et-al [4] and Palekar [8] shown in Fig.(6) exhibits approximately good agreement between present work and Lee et al work for whole $(\Lambda)$ range with while present work exhibits approximately a good agreement with Palekar work only in the wedge parameter $(\Lambda)$ range between 0.25 to 0.5 .

The comparison for the UHF heating situation with Palekar [8] shown in Fig. (7) reveals that the present work has a similar trend obtained by Palekar but the rate of local heat transfer change in the present investigation with wedge parameter $(\Lambda)$ is higher than the rate obtained by Palekar[8].

For $\beta$ parameter $=1$, Fig. (8) shows the comparison of friction factor $\left(C_{f}\right)$ (obtained from equ.36) with the wedge parameter $(\Lambda)$, for the present work with Lee et-al [4] and Palekar [8] work. This figure reveals a good agreement between present works with previous works.

\subsubsection{In a still fluid}

In this section an analytical solution results presented for still (quiescent) flow over a rotating sphere with constant wall temperature heating condition. Fig. (9) shows the variation of $\left(\mathrm{Nu}_{\mathrm{av}}\right)$ with a high range of $\mathrm{Re}_{\mathrm{r}}$ for different $(\mathrm{Pr})$ number. This variation is presented in equation (55). The result reveals clearly that the heat transfer coefficient improved as Reynolds and $\mathrm{Pr}$ number increasing as the $\left(\mathrm{Nu}_{\mathrm{av}}\right)$ increases with the increasing of $\left(\mathrm{Re}_{\mathrm{r}}\right)$ and $(\mathrm{Pr})$ numbers.

Fig. (10) shows a comparison between the present investigation (according to present Eq. (55)) and previous works presented by kreith et-al[16], Banks [17], Dorfman, and Mironova [17] and Estop [20] depicted as the variation of the $\left(\mathrm{Nu}_{\mathrm{av}}\right)$ with high range of $\mathrm{Re}_{\mathrm{r}}$, for $\mathrm{Pr}$ is equal to 0.7 (i.e. air). The present result shows a good agreement with the previous works. As $\left(\mathrm{Nu}_{\mathrm{av}}\right)$ value increases with the increasing of $\mathrm{Re}_{\mathrm{r}}$ numbers. The present result fell in the middle of the previous available similar work as present result (Eq.(55)) higher than Banks[17] result and Dorfman, and Mironova [18] result and lower than kieth et-al.[19] result and Estop [21] result. The Present result (Equ. (55)) was compared with Kreith et. al.[16] result in the form of variation of $\left(\mathrm{Nu}_{\mathrm{av}}\right)$ with wide range of $\mathrm{Re}_{\mathrm{r}}$, , and for the Pr number is equal to (10 and 100) is shown in Fig. (11). The comparison exhibits a good agreement for the low Pr number for a whole range of $\mathrm{Re}_{\mathrm{r}}$ up to $10^{5}$, while a poor agreement for high $P r$ number for $\operatorname{Re}_{\mathrm{r}}$ higher than $10^{4}$.

\subsection{Mass transfer calculations from a rotating sphere}

The heat transfer analogy was applied here to obtain the mass transfer equations from the heat transfer equations for the same cases and conditions. Therefore we will just replace the parameters of heat to mass and these are: Rer and Reo will be the same, while Prandtl number (Pr) will be Schmidt number
(Sc) and Nusselt number ( $\mathrm{Nu}$ ) will be Sherwood number (Sh). This note made to get the attention for the equations.

\subsubsection{In an axial flow}

In Fig. (12) the variation of the $\left(\mathrm{Sh}_{\mathrm{av}}-1\right)$ with Reynolds number for Schmidt number is $(0.7)$, and for different $(\beta)$ parameter is $(1,4$ and 10) is depicted. The figure exhibits a sharp increase in mass transfer rate at low Reynolds number then the rate of increment gradually decreases at high Reynolds number. Also mass transfer shows a slightly increasing with increase of $\mathrm{B}$ parameter. The comparison between present result and Furuta et-al [23] experimental and analytical results is presented as the variation of $\left(\mathrm{sh}_{\mathrm{av}}-1\right)$ with Reynolds number is presented in Fig.(13) and Fig. (14). For Schmidt number equal to (0.7) and $\beta$ parameter equal to 1 . Fig. (13) exhibits a good agreement between present analytical result and Furuta et-al[23] analytical result and both far from Furuta et-al[23] experimental result. Fig. (14) shows the comparison for Schmidt number equal to 10 and $\beta$ parameter equal to 10 and it exhibits a complete agreement between present result with experimental and analytical result presented by Furuta et-al [23].

\subsubsection{In Still Fluid}

The analogy between the heat and the mass transfer is applied to obtain the mass transfer coefficients for rotating sphere in a still fluid which was presented in Eq. (59). Fig. (15) shows the variation of $\left(\mathrm{Shav} / \mathrm{Sc}^{1 / 2}\right)$ with $\mathrm{Re}_{\mathrm{r}}$, for wide range of $\mathrm{Re}_{\mathrm{r}}$ numbers, and reveals mass transfer increasing with the increasing of $\mathrm{Re}_{\mathrm{r}}$

\section{CONCLUSIONS}

In general the following conclusions are drawn from the present study:

A new equation was obtained analytically for the heat transfer from a rotating sphere in still fluid and the derived theoretical results were compared with the available experimental and theoretical results. The ratio $\left(\mathrm{Nu}_{\mathrm{x}} / \mathrm{Re}_{\infty}{ }^{1 / 2}\right)$ increased slightly with the increasing of the wedge parameter $(\Lambda)$, and rapidly with the increasing of Prandtl number $(\operatorname{Pr})$. The ratio of the local Nusselt number to Reynolds number $\left(\mathrm{Nu}_{\mathrm{x}} / \mathrm{Re}_{\infty}{ }^{1 / 2}\right)$ for (UWT/UHF) in an axial flow increasing as the wedge parameter $(\Lambda)$ and as Prandtl number $(\operatorname{Pr})$ increased, while was slightly affected by the rotation parameter $(\beta)$. The friction factor $\left(\mathrm{C}_{\mathrm{f}}\right)$ is increasing with the increase of the rotation parameter $(\beta)$, for the rotating sphere in an axial flow. The average Nusselt number increases rapidly with the increasing of Prandtl number and slightly increases with the rotation Reynolds number $\mathrm{Re}_{\mathrm{r}}$ for the heat transfer from a rotating sphere in sill fluid. The heat transfer of the rotating sphere in an axial flow for (UHF) heating condition is greater than the (UWT) heating condition for the same $(\beta)$ parameter and $(\mathrm{Pr})$. The ratio of $\left(\mathrm{Nu}_{\mathrm{x}} / \mathrm{Re}_{\infty}{ }^{1 / 2}\right)$ is increased with the increasing of wedge parameter $(\Lambda)$. and Prandtl number $(\operatorname{Pr})$.

The ratio of $\left(\mathrm{Sh}_{\mathrm{x}} / \mathrm{Re}_{\infty}{ }^{1 / 2}\right)$ is increased slightly with the increasing of wedge parameter $(\Lambda)$ and rapidly with the increasing of Schmidt number for the axial flow. The average Sherwood number $\left(\mathrm{Sh}_{\mathrm{av}}\right)$ for the still fluid is increased with the increasing of Schmidt number $(\mathrm{Sc})$ and rotational Reynolds number $\left(\mathrm{Re}_{\mathrm{r}}\right)$.

\section{ACKNOWLEDGMENT}

The author gratefully acknowledges the financial support for this study received from the Energy Department, College of Engineering, University of Baghdad 


\section{REFERENCES}

[1] Siekmann, J., "The calculation of the thermal boundary layer on rotating sphere," Z. Angew. Math phys., Vol. 16,1957 , pp. $468-482$.

[2] Hoskin, N. E., "The laminar boundary layer on a rotating sphere," in: H. Gortter and W. Tollemien, 50 Jahre Grenzschichtforchung (Friedr Vieweg U. Sohn, Brunswig), 1955, pp. $127-131$.

[3] Chao, B. T., and Greif, R., "Laminar forced convection over rotating bodies," ASME J. of Heat Transfer, Vol. 96, 1974, pp. $463-466$.

[4] Lee, M. H., Jeng D. R., and Witt, K. J., "Laminar boundary layer transfer over rotating bodies in forced flow," ASME J. Heat Transfer, Vol. 100, 1978, pp. 496 502 .

[5] Merk, H. J., "Rapid calculations for boundary layer transfer using wedge solutions and asymptotic expansions," J. of Fluid Mechanics, Vol. 5, 1959, pp. 460 -480 .

[6] Konno, H., Asano, M., Kuriyama, M., and Harada, E., "Heat transfer from rotating sphere," Kagaku Kogaku Ronbunshu, Vol. 4, 1978, pp. 221 - 230.

[7] Le Palec, G., and Daguenet, M., "Analysis of free convective effect about a rotating sphere in forced flow," Int. Communication Heat Mass Transfer, Vol. 17, 1984, pp. $409-416$.

[8] Palekar, M. G., and Rajasekaran, R., "Mixed convection about a rotating sphere," Int. J. Heat Mass Transfer, Vol. 28, 1985, pp. $959-968$

[9] Le Palec, G., and Daguenet, M., "Laminar threedimensional mixed convection about a rotating sphere in a stream" Int. J. Heat Mass Transfer, Volume 30, Issue 7, July 1987, Pages 1511-1523.

[10] Georges Le Palec, "A new correlation for laminar mixed convection over a rotating sphere." Int. J. Heat Mass Transfer, Vol. 31, issue 11, 1988, pp. 2347 - 2355

[11] Al- Jamal, K., El - Shaarawi, M. A. I., and Kodah, Z., "Laminar forced convection about rotating bodies at low Pr - number," Heat and Mass Transfer, vol. 33, No. 1 2, 1997, pp. $81-84$. (Internet searching).

[12] Hossain, M. A. and Takhar, H. S., "Radiation conduction interaction in mixed convection a long rotating bodies," Heat and Mass Transfer, vol. 33, No. 3, 1997, pp. 201 - 208. (Internet research).

[13] Stokes, S. G. G., "On the theories of the inertia friction of fluid in motion," Camb. Trans., Vol. 8, 1845, pp. 287 $-293$.

[14] Howarth, L., "Note on the boundary layer on a rotating sphere," Phil. May., Vol. 42, 1951, pp. 1308 - 1315.

[15] Nigam, S. D., "Note on the boundary layer on a rotating sphere.” Appl. Sci. Res., Vol. Ag. 1960, pp. 197 - 205.

[16] Kreith, F., Roberts, L. G., Sullivan, J. A., and Siha, S. N., "Convection heat transfers and flow phenomena of rotating spheres," Int. J. Heat Mass Transfer, Vol. 6, 1963 , pp. $881-895$.
[17] Banks, W. H., "The boundary layer on a rotating sphere," Quarterly J. of Mechanics and Applied Mathematics, Vol. 18, 1965, pp. 443 - 454.

[18] Dorfman, L. A., and Mironova, V. A.,"Solutions of equations for the thermal boundary layer at rotating axisymmetric surface," Int. J. Heat Mass Transfer, Vol. B, 1970, pp. $81-92$.

[19] Acrivos, A. , "Heat transfer at high Peclet number from a small sphere freely rotating in a simple shear field," J. Fluid Mechanics, Vol. 46, part 2, 1971, pp. 233 - 240.

[20] Frankel, N. A., and Acrivos, A., "Heat and mass transfer from small spheres and cylinders suspended in shear flow," phys. Fluids, Vol. 11, 1968, pp. $1913-1918$.

[21] Eastop, T. D., "The influence of rotating on the heat transfer from a sphere to an air stream," Int. J. Heat Mass Transfer, Vol. 16, 1973, pp. 1954 - 1957

[22] Poe, G. G., and Acrivos, A. ,'Closed streamline flows past small rotating particles, heat transfer at high Peclet numbers," Int. J. Multiphase Flow, Vol. 2, 1976, pp. 365 -377 .

[23] Furuta, T., Jimbo, T., Okazaki, H., and Toei, R., "Mass transfer to a rotating sphere in an axial stream," J. Chemical Engineering. Japan, Vol. 8, 1975, pp. $456-$ 462 .

[24] Furuta, T., Okazaki, M., and Toei, R., "Mass transfer to a rotating sphere in a stream," J. Chem. Engg Japan, Vol. 10, 1977, pp. $288-292$.

[25] Chao, B. T., and Fagbenle, R. O., "On Merk's method of calculating boundary layer transfer," Int. J. of Heat Mass Transfer, Vol. 17, 1974, pp. 223 - 240.

[26] Zaturska, M. B., and Banks, W. H. H., "On family of Stockes flow," Int. J. for Numerical Methods in Fluids, Vol. 4, 1984, pp. 685 - 699.

[27] Carslaw, H.S., and Jeager, J.C. "Conduction of Heat in Solids" $2^{\text {nd }}$ Ed. Oxford University Press, London and Newyork, 1959

[28] Meyers, G. E., "Analytical method in conduction heat transfer," MC-Graw Hill, Inc., 1971.

\section{APPENDIX}

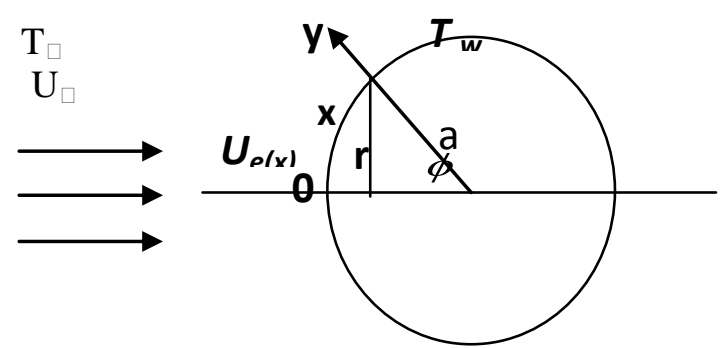

Fig.(1) The geometry of the case 


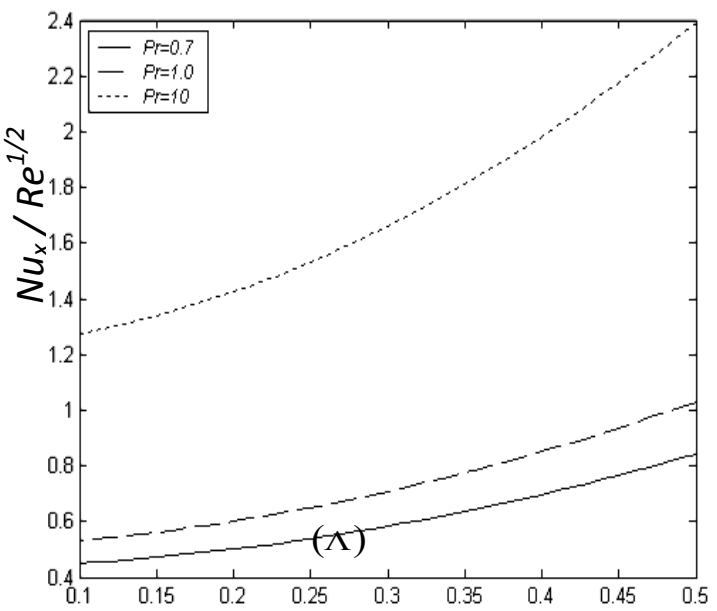

Fig.(2) Variation of $\left(\mathrm{Nu}_{x} / \mathrm{Re}^{1 / 2}\right)$ with wedge parameter ( $\Lambda$ ), for (UWT) case, different Prandtl number and (B)parameter equal to 1.

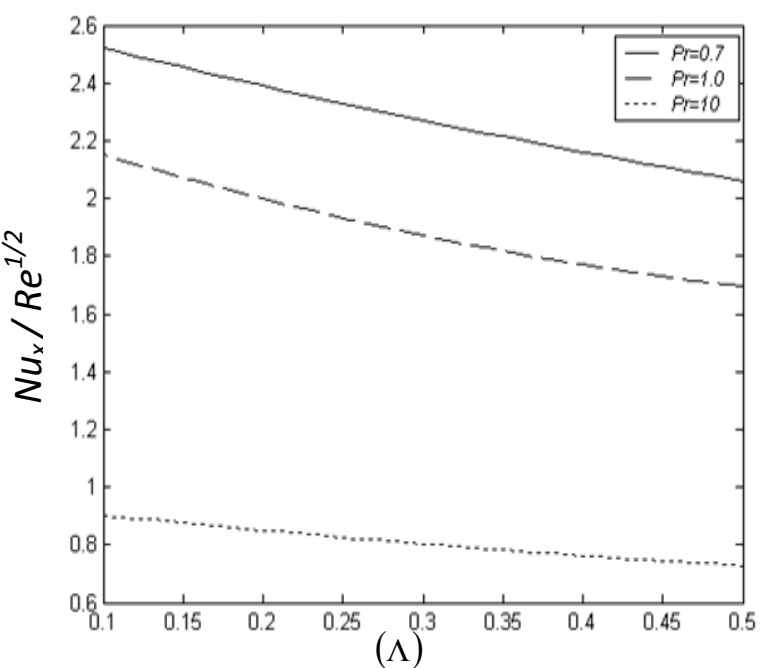

Fig.(3) Variation of $\left(\mathrm{Nu}_{x} / \mathrm{Re}^{1 / 2}\right)$ with wedge parameter $(\Lambda)$, for (UHT) case, different Prandtl number and (B) parameter equal to 1

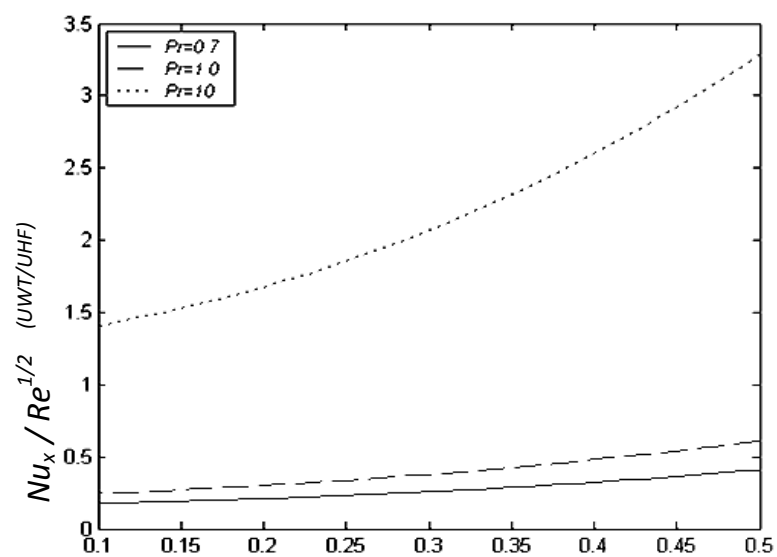

$(\Lambda)$

Fig.(4) Variation of $\left(\mathrm{Nu}_{x} / \mathrm{Re}^{1 / 2}\right)$ with wedge parameter $(\Lambda)$, for the cases ratio (UWT) to (UHT), for different Prandtl number and (B) parameter equal to 1

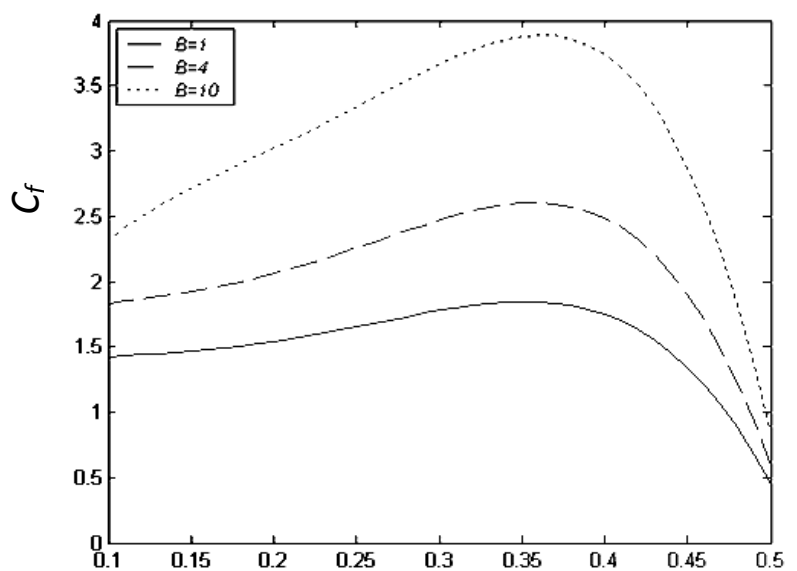

$(\Lambda)$

Fig. (5) Variation of the friction factor $C_{f}$ with wedge parameter $(\Lambda)$, for different (B) parameter values.

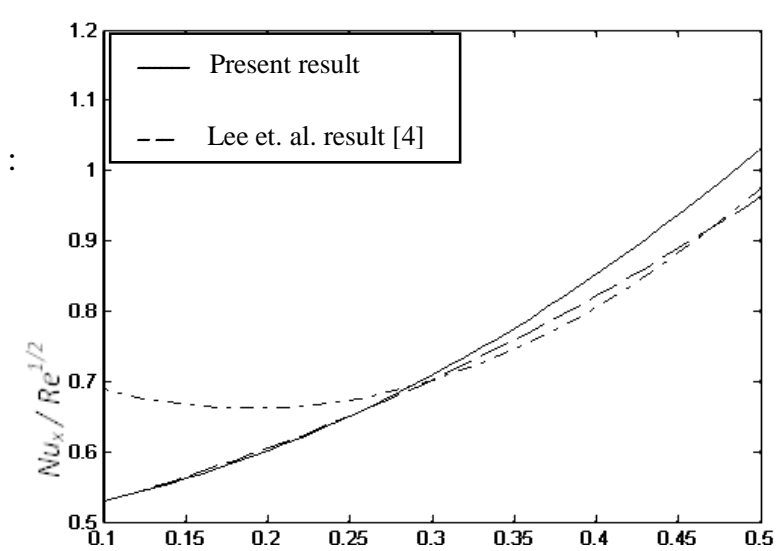

$(\Lambda)$

Fig.(6) Comparison of the present result with Lee et. al. and Palekar results, for $\operatorname{Pr}=1, B=1$, and (UWT) case.

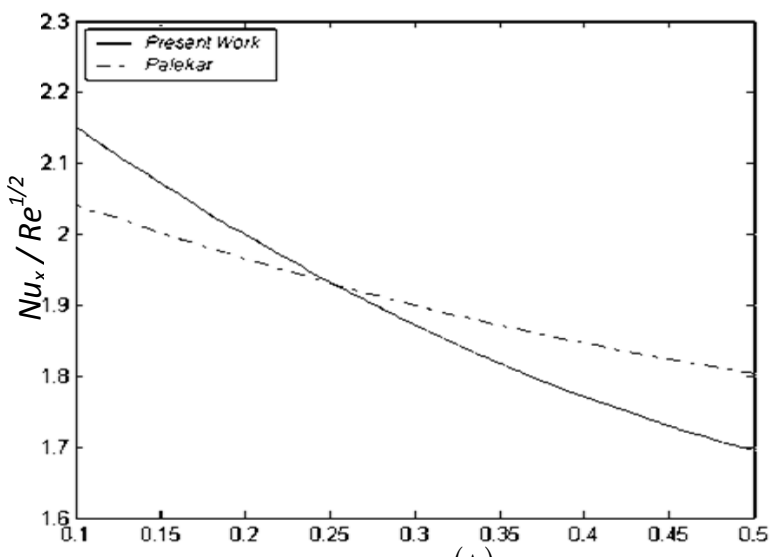

$(\Lambda)$

Fig. (7) Comparison of the present result with Palekar result, for $(\operatorname{Pr})=1.0, \mathrm{~B}=1$, and (UHF) case. 


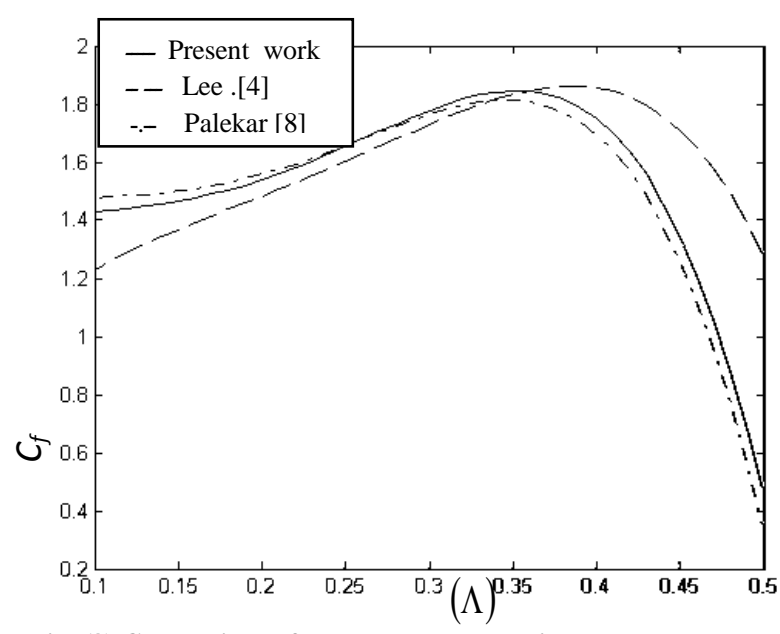

Fig. (8) Comparison of the present result with Lee et-al. and Palekar results, for the friction factor with $B=1$

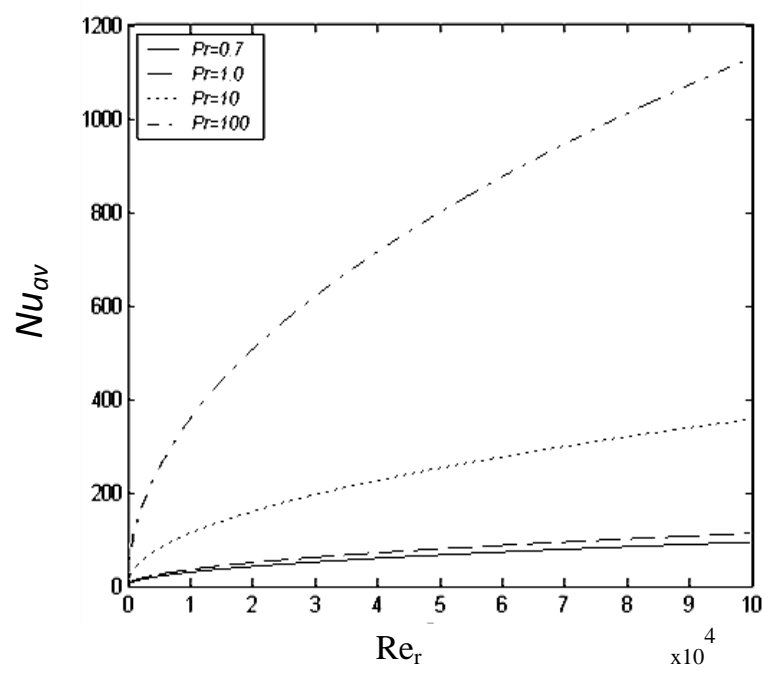

Fig. (9) Variation of Nusselt number with Rotational Reynolds number, for different Pr values

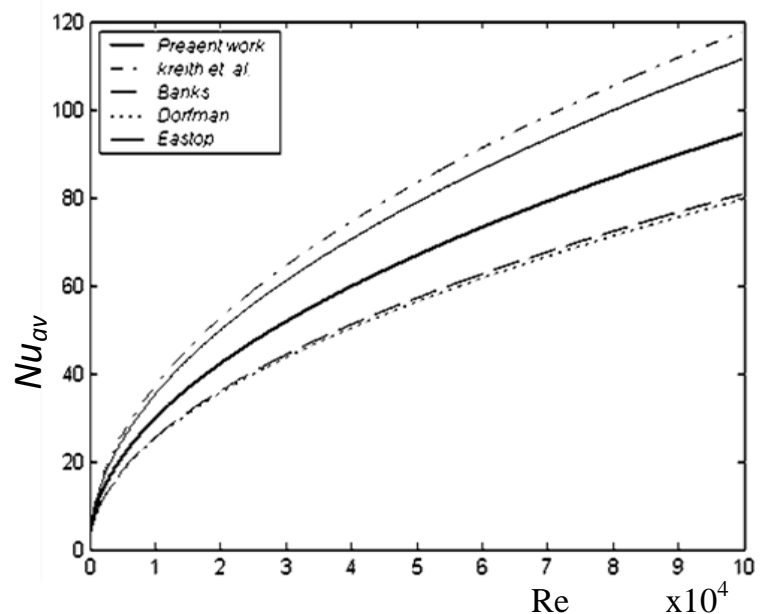

Fig. (10) Comparison of the present result with the results of Banks, Dorfman, Eastop and Kreith et. al. for $(\operatorname{Pr})=0.7$

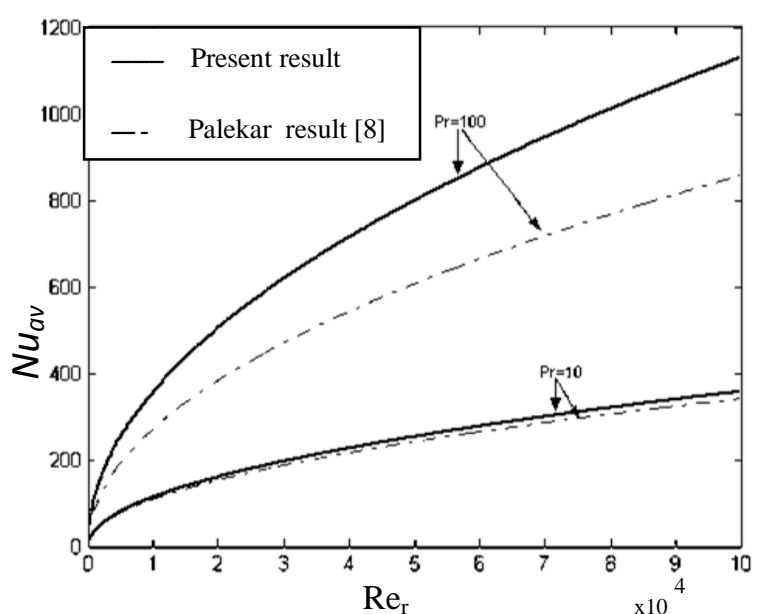

Fig. (11) Comparison of the present result with Kreith et-al. result, for $(\operatorname{Pr})=10$ and 100 .

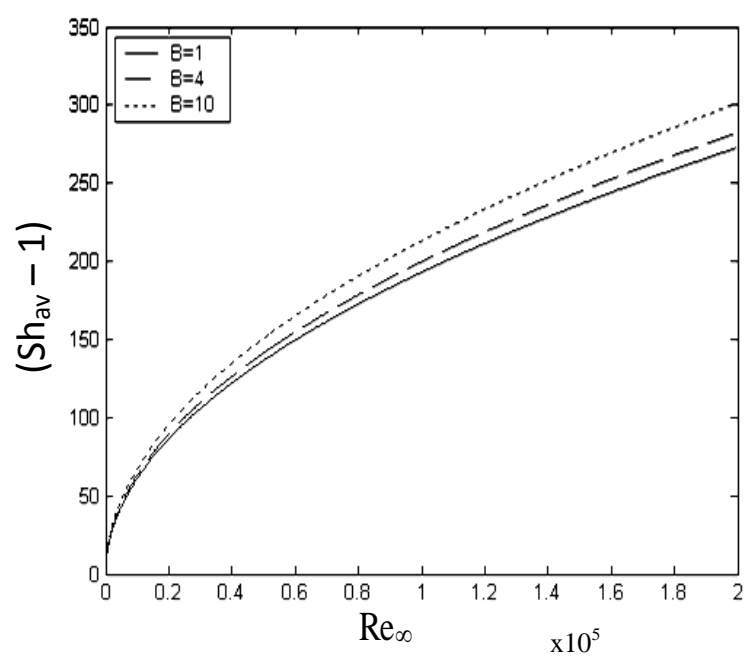

Fig. (12) Variation of (Shav -1) with Reynold number, for different (B) parameter and for $\mathrm{Sc}=\mathbf{0 . 7}$

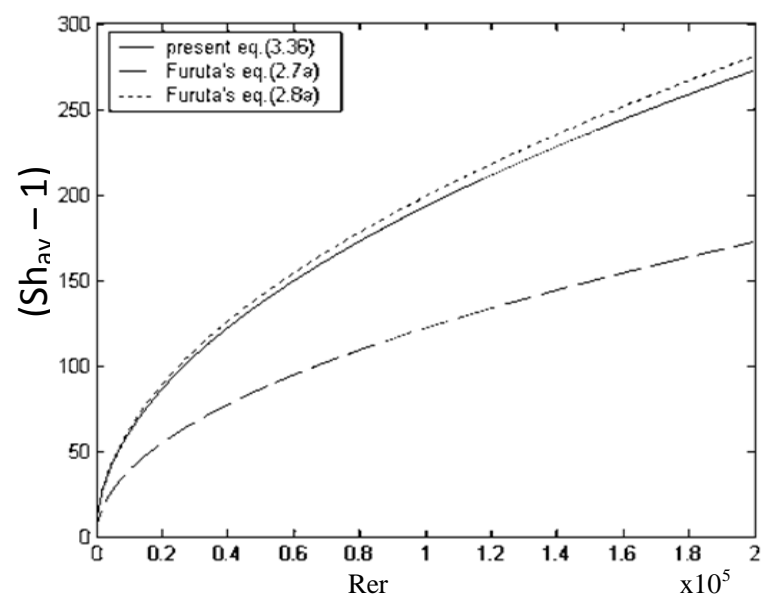

Fig. (13) Comparison of the mass transfer present result with Furuta's experimental and theoretical results, for $\mathrm{Sc}=0.7$ and for $(\mathrm{B}=1)$ 


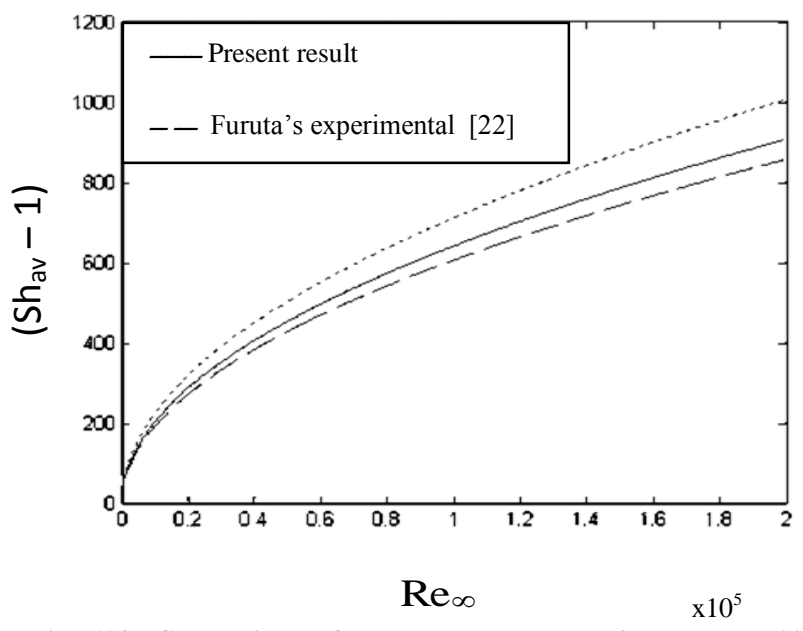

Fig. (14) Comparison of the present result with Furuta [22] .experimental and theoretical results, for $\mathrm{Sc}=\mathbf{1 0}$ and $\mathrm{B}=\mathbf{1 0}$

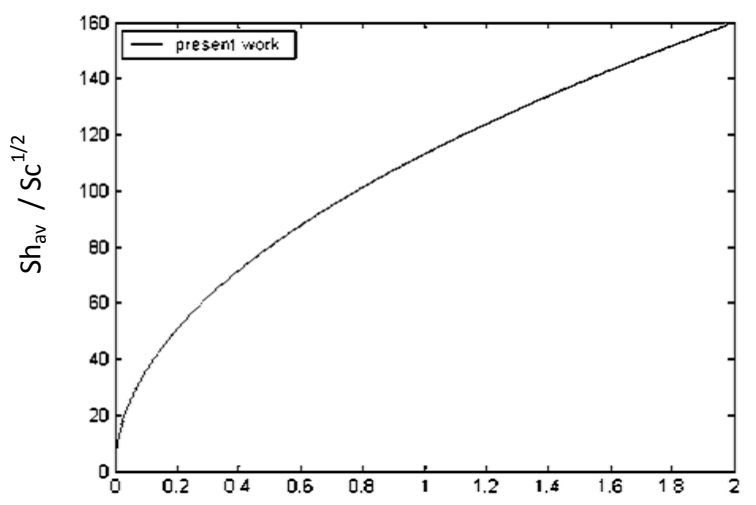

$\mathrm{Re}_{r}$

$\mathrm{x} 10^{5}$

Fig.(15) Variation of (Shx/Sc $\left.{ }^{1 / 2}\right)$ with a wide range of Reynolds No.

\section{Nomenclature}

The symbols used have the following meanings, unless otherwise stated in the text.

\begin{tabular}{|c|c|c|}
\hline $\mathrm{a}$ & Radius of sphere & (m) \\
\hline 1 & Thermal conductivity & $\mathrm{W} / \mathrm{m} \cdot{ }^{\circ} \mathrm{C}$ \\
\hline Q & Total heat transfer rate from sphere & (W) \\
\hline q & Heat flux & $\left(\mathrm{W} / \mathrm{m}^{2}\right)$ \\
\hline & Radius of body at $\mathrm{x}$ & (m) \\
\hline$S$ & Surface area of sphere & (m) \\
\hline $\mathrm{T}$ & Temperature & $\left({ }^{\circ} \mathrm{C}\right)$ \\
\hline $\mathrm{U}$ & Free stream velocity & $(\mathrm{m} / \mathrm{sec})$ \\
\hline $\mathrm{u}$ & Velocity component in the $\mathrm{x}$ direction & $(\mathrm{m} / \mathrm{se}$ \\
\hline $\mathrm{Ue}_{(\mathrm{x})}$ & $\begin{array}{l}\text { Velocity of the main stream at the edge } \\
\text { boundary layer }\end{array}$ & $\begin{array}{l}\text { e of the } \\
(\mathrm{m} / \mathrm{sec})\end{array}$ \\
\hline $\mathrm{v}$ & Velocity component in the y direction & $(\mathrm{m} / \mathrm{sec})$ \\
\hline $\mathrm{W}$ & $\begin{array}{l}\text { Velocity component in the rotating } \\
\text { direction }\end{array}$ & \\
\hline $\mathrm{x}$ & $\begin{array}{l}\text { Coordinate measured along surface } \\
\text { from front stagnation point }\end{array}$ & (m) \\
\hline $\mathrm{y}$ & \multicolumn{2}{|l|}{$\underline{\text { Dimensionless symbols }}$} \\
\hline $\mathrm{B}$ & Rotation parameter, defined in Eq. (19) & \\
\hline $\mathrm{C}$ & Constant, defined in Eq.(49) & \\
\hline $\mathrm{C}_{\mathrm{f}}$ & Friction factor, define in Eq. (35) & \\
\hline $\mathrm{f}$ & Dimensionless stream function, Eq.(9) & \\
\hline g & $\begin{array}{l}\text { Dimensionless rotating velocity, defined } \\
\text { Eq. (12) and gravitational acceleration }\end{array}$ & \\
\hline
\end{tabular}

in Grashof number

Gr Grashof number

$\mathrm{Nu} \quad$ Nusselt number

Pr Prandtl number

$\operatorname{Re}_{\mathrm{r}} \quad$ Rotational Reynolds number

$\operatorname{Re}_{\infty} \quad$ Reynolds number

Sc Schmidt number

Sh Sherwood number

Ta Taylor number

Pe Peclet number (Re.Pr)

\section{Greek symbols}

Angular velocity

Thermal diffusivity

$(1 / \mathrm{sec})$

The angel between the direction of

flow and the axis of rotation in

and expansion coefficient used in

Grashof No.

Density

$\left(\mathrm{m}^{2 /} \mathrm{sec}\right)$

Kinematics viscosity

Kinetic viscosity

Dimensionless temperature,

Dimensionless y coordinate, Eq (8)

Dimensionless x coordinate, Eq (7)

Stream function, defined in $\quad \mathrm{Eq}(9)$

Wedge parameter, defined in $\mathrm{Eq}(13)$

\section{Subscript}

Zero order differential equation

First order differential equation

Second order differential equation

The wall temperature of sphere, for the still

fluid case

Average

Rotation

The wall temperature of sphere, for the axial

flow case

local

Infinite ambient, free stream

\section{Superscript}

First derivative

Second derivative

Third derivative 